\title{
Biology and Host Preference of Odoiporus longicollis Oliver, (Banana pseudostem weevil)
}

\author{
Jithu U. Krishnan ${ }^{1}$, C. A. Jayaprakas ${ }^{2}$ \\ ${ }^{1,2}$ Biopesticide laboratory, Division of Crop Protection, ICAR- Central Tuber Crop Research Institute, Thiruvananthapuram, Kerala, India
}

\begin{abstract}
Banana, one of the oldest fruits known to mankind, is world's fourth most important food crop after rice, wheat and maize. Bananas and plantains are cultivated over 100 countries throughout the tropical and sub-tropical regions to an area of 4.953 million hectares with an annual production of around 101.993 million tonnes. India ranks 1st with a total production of 24.869 million tonnes from an area of 0.722 million hectares, however the production is severely affected due to the infestation by a spectrum of insect pests at various stages of the crop. Odoiporous longicollis Oliver, commonly known as banana pseudo stem weevil (BPW), is the major pest of banana, causing 10-90\% yield loss. Infestation by BPW, a pest originated from South and South East Asia, is a growing constraint in banana cultivation. Management of this noxious pest is widely relied upon synthetic chemicals, but a detailed study regarding the biology of $O$. longicollis will be helpful for making simulation models to forecast pest incidence, and to prepare for its management. The current study focuses on the biology and host preference of BPW.
\end{abstract}

Keywords: Banana weevil, Host range, Curculionidae, Biology, Fecundity

\section{Introduction}

Banana occupies the first position among the40 million tonnes of fruits produced in India(NHBSTAT 2014, FAOSTAT 2014). Ravage of pests is the prime constraint in the production and productivity of banana (Visalakshiet al., 1989). Of the three weevil pests reported, Odoiporuslongicollis Olivier, commonly known as banana pseudostem weevil (BPW), is the most noxious monophagous pest than the other two viz. CosmopolitussordidusGermer (banana rhizome weevil) and PolitusmellerborgiBough (small banana weevil), infesting banana in the field at its multiple stages.

The pest BPW enjoys a wide distribution throughout the tropics, and advancement of infestation by the weevil during the late pre-flowering stage culminates in the failure of ascending flower bud and peduncle (Padmanabhanet al. 2001). Incidence of BPW has been reported from different parts of India and it is becoming very serious in Southern India, particularly in Tamil Nadu and Kerala (Reghunathet al., 1992; Justin et al., 2008). The oviposition punctures inflicted by female weevils and the tunnels made by the grubs turn the plant fragile and weak, causing premature falling (Ravi and Palaniswami, 2002; Anitha and Nair, 2004). Infestation by weevil perpetrates hefty crop loss (Padmanaban and Sundaraju, 1999; Gold et al., 2001a) to a tune of $10-90 \%$, depending on the intensity of ravage and management efficiency (Prasunaet al., 2008). Chemical insecticides invite unwarranted long-term effect, including insecticide resistance (Gold and Messiaen, 2000), pest resurgence, pest outbreak, ground water contamination and radical effects on beneficial insects (David, 2008), apart from the environmental imbalances due to tottering ecosystem. To lessen the adversaries of chemical pesticides on man and environment, a global drive is set off for exploring alternative green technologies to contain insect pests in cropping system. As this technology is targeted to the life stages of the pest, it is imperative to explore biology of the pest to formulate effective packages for pest management strategies.

\section{Materials and Methods}

Adults and grubs of Odoiporuslongicollis collected from the banana fields of Thiruvananthapuram district were maintained in the laboratory at $26 \pm 3^{\circ} \mathrm{C}, 60 \pm 10 \% \mathrm{RH}$ and L:D 12:12. The pupae collected were maintained separately in $100 \mathrm{ml}$ plastic containers, and each container was covered with muslin cloth. On emergence, the adults were transferred into one litre plastic container and they were provided pieces of pseudostem for feeding. Subsequently population of 30 weevils each were maintained in 2L plastic jars with almost one $\mathrm{kg}$ pseudostem. The food was replaced every two weeks before it gets dried or putrefied. The newly emerged adults were segregated and maintained in jars for experiments.

\section{Biology}

Biology of the insect was studied in the laboratory $\left(26 \pm 3^{\circ} \mathrm{C}, 60 \pm 10 \% \mathrm{RH}\right.$ and L:D 12:12). Fecundity, life cycle, feeding efficiency and behaviour of each instar, host searching and host varietal preferences were studied. Images were captured by camera (Nikon- COOLPIX L110, 12.1MP.) under required zoom.

\section{Fecundity}

Cocoons collected from the infested plants were individually reared in $100 \mathrm{ml}$ plastic cups with moistened tissue paper (Giblin-Davis et al. 1989) at $28 \pm 4^{\circ} \mathrm{C}$ until adult emergence. On emergence, one male and one female each of 13 days old were confined for mating in a $100 \mathrm{~mL}$ plastic container for 24 hours, and they were provided pseudostem pieces of $4 \times 3 \mathrm{~cm}$ for feeding and egg laying. In order to understand the mating frequency and fecundity, two sets of experiment were conducted; one with female exposed to male only for $24 \mathrm{~h}$ whereas in the other set male and females were exposed continuously till their death. Five replications were maintained. The experiment was conducted in a environmental chamber (Fourtech) at $29^{\circ} \mathrm{C}$ with photoperiod of 12:12 (L:D) $60 \% \mathrm{RH}$ ). The pseudostem was removed every day and the eggs were observed with the help of incandescent bulb $(100 \mathrm{~V})$. The fecundity was compared between short term and long term mating. 


\section{International Journal of Science and Research (IJSR) \\ ISSN (Online): 2319-7064}

Index Copernicus Value (2013): 6.14 | Impact Factor (2015): 6.391

\section{Incubation Period}

The eggs collected were placed in Petri dishe $(60 \times 15 \mathrm{~mm})$ lined with wet filter paper, and these were placed in environmental chamber at $29^{\circ} \mathrm{C}$. The incubation period and hatching percentage were calculated. The Pearson's correlation test was applied to study the change in fecundity due to short term and long term mating of the BPW.

\section{Instars}

On hatching, the grubs were transferred into plastic tubes of $40 \mathrm{ml}$ capacity with fresh pseudostem (30g) as food. Morphometry of all the stages were recorded. Pupation was artificially created by transferring the pre-pupa stage into amber coloured tubes of $2 \mathrm{ml}$ capacity with proper ventilation

Feeding efficiency of the grubs at different instars was studied in the laboratory. Grubs of different instars were transferred into $100 \mathrm{ml}$ plastic containers and were provided $50 \mathrm{gm}$ of pseudostem for feeding. Container with the same quantity of feed, but no grubs was kept as control to study the natural water loss during the treatment. Observations on the weight loss were recorded on every $24 \mathrm{~h}$. Ten replications were maintained for each treatment and feeding efficiency was continuously monitored for 5 days in each treatment.

The distance tunnelled and the tunnelling pattern of all the stages including adults was recorded. Pieces of pseudostem of $25 \mathrm{~cm}$ height, upper and bottom diameters 12 and $14 \mathrm{~cm}$ respectively, were exposed to individual stages of the weevil. Three replications were maintained. After 5 days, the tunnelling pattern and distance travelled by each instar was recorded. The pseudostem was made into thin slices and the feeding track was measured by inserting twine from the feeding point to the farthest. The diameter of the tunnels made by each stage was also recorded.

\section{Longevity}

Study was conducted with ninety eggs collected from the nucleus culture, and on hatching, the grubs were maintained on pseudostem at $26 \pm 3^{\circ} \mathrm{C}, 60 \pm 10 \% \mathrm{RH}$ and L:D 12:12. Freshly emerged adults 60 nos. were grouped 20 each (male to female 1:1) and maintained in plastic jars with pseudostem as food for longevity assessment.

\section{Host preference}

Study on the varietal preference of banana to BPW was conducted at the laboratory by 'choice test' method. Fresh pseudo stems collected from four varieties of banana (Musa AAB Cv. Nendran, Musa ABB Cv. Kappa, Musa AAA Cv. Morris and Musa AB Cv. Njalipoovan) were cut into square pieces of $3 \times 3 \mathrm{~cm}$ with an average thickness of $1.2 \pm 0.2 \mathrm{~cm}$, and placed at equidistance at the boundary of a Petri dish (17cm dia.). Adult weevil, irrespective of sex (5nos.), starved for $24 \mathrm{~h}$ were released at the centre of the Petri dish and it was covered with its lid. A black cloth was wrapped over the Petri dish, and after three minutes the Petri dish was opened and the no. of weevils attracted into each variety was noted. Ten replications of the experiment were maintained.

\section{Results}

\section{Biology}

Fecundity, life cycle, feeding efficiency and behaviour of each instar, host searching and host varietal preferences were studied and the following results were observed.

\section{Fecundity}

Fecundity of female that was exposed to male for $24 \mathrm{~h}$ was estimated to be $62.0 \pm 1.2$, whereas female exposed to male

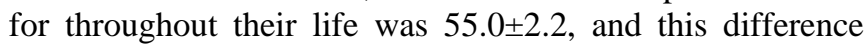
was statistically significant $(\mathrm{P}=0.949)$ (Fig.1). Egg viability was also found significantly different between single day and multiple days exposure $(\mathrm{P}=0.966)$. In the former case, viability of eggs was $70.92 \pm 1.43 \%$ whereas in the latter, it was $84 \pm 3.66 \%$ (Fig.2).Eggs are creamy white, elliptical, leathery and measured $1.877 \pm 0.062 \mathrm{~mm}$ long and $0.911 \pm 0.010 \mathrm{~mm}$ wide.

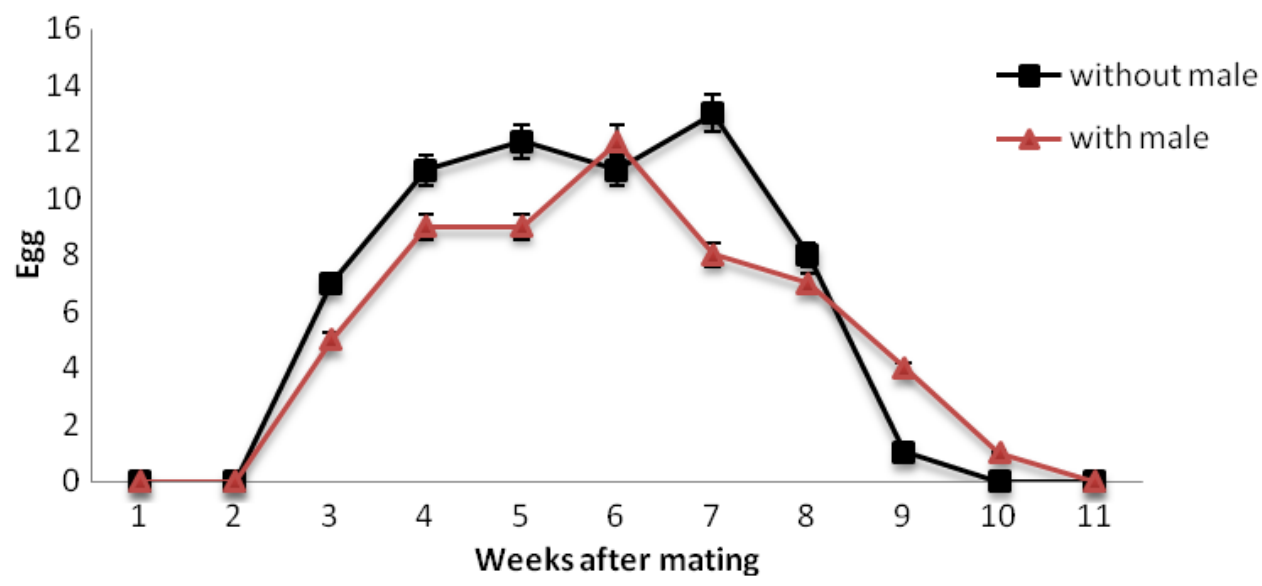

Figure 1: Egg laying pattern of Odoiporus longicollis $(\overline{\mathrm{X}} \pm \mathrm{SE} ; \mathrm{r}=3 ; \mathrm{n}=20)$ 


\section{International Journal of Science and Research (IJSR) \\ ISSN (Online): 2319-7064}

Index Copernicus Value (2013): 6.14 | Impact Factor (2015): 6.391

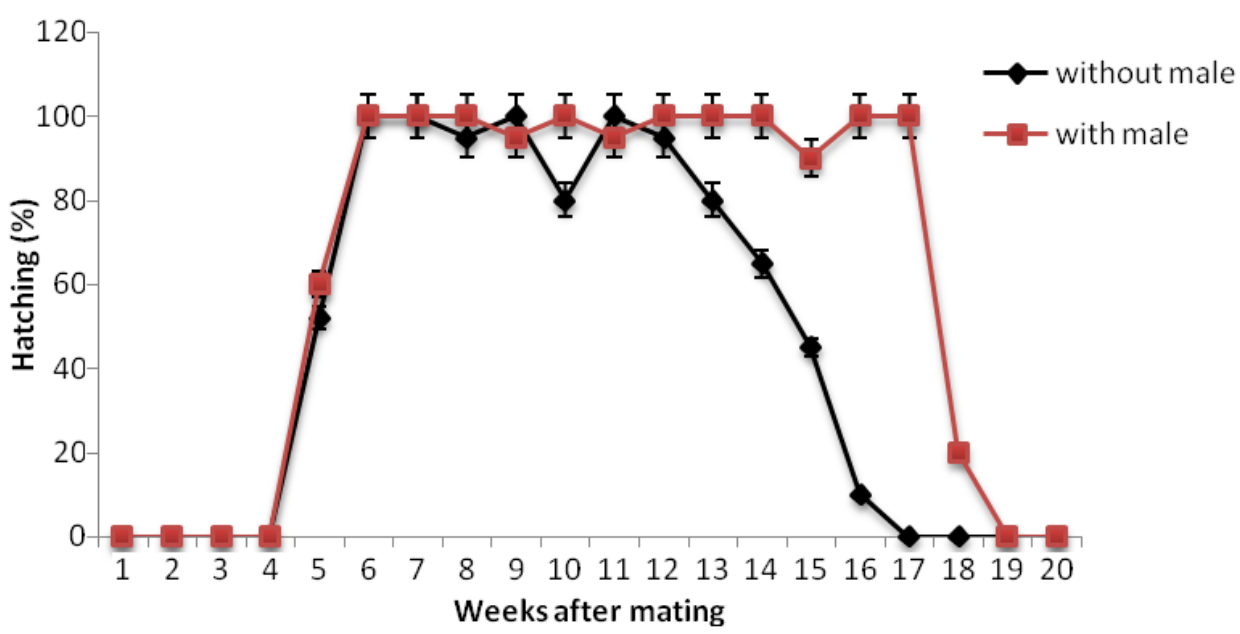

Figure 2: Viability of eggs ofOdoiporus longicollis during different days

$(\overline{\mathrm{X}} \pm \mathrm{SE} ; \mathrm{r}=3 ; \mathrm{n}=20)$

Incubation period: Incubation period is $4.5 \pm 0.71$ day and egg viability was $94.0 \% \pm 1.3$.

Instars: First instar grub is elongate, crystalline white with a prominent golden brown head that occupies $1 / 3^{\text {rd }}$ of its body with well-developed mouth parts (Fig. 3). Size is $3.45 \pm 0.062 \mathrm{~mm}$ long and $1.56 \pm 0.010 \mathrm{~mm}$ wide, approximately twice that of egg.The $1^{\text {st }}$ instar grub feeds $2.18 \pm 0.262 \mathrm{~g}$ of pseudostem (Table 1 ),

Table 1: Feeding rate of different grub stages of Odoiporus longicollis.

\begin{tabular}{|l|l|l|l|l|l|l|}
\hline \multirow{2}{*}{$\begin{array}{l}\text { Instar } \\
\text { Instar }\end{array}$} & \multicolumn{5}{|c|}{$\begin{array}{c}\text { Pseudostem feeding (\%) } \\
\text { Age of the grub (Day) }\end{array}$} & \multirow{2}{*}{ Average feeding (\%) } \\
\cline { 2 - 6 } & 1 & 2 & 3 & 4 & 5 & \\
\hline 1 & $0.07 \pm 0.01^{\mathrm{d}}$ & $0.24 \pm 0.06^{\mathrm{d}}$ & $1.36 \pm 0.14^{\mathrm{d}}$ & $3.84 \pm 0.23^{\mathrm{d}}$ & $5.41 \pm 0.87^{\mathrm{d}}$ & $2.18 \pm 0.262^{\mathrm{d}}$ \\
\hline 2 & $0.39 \pm 0.80^{\mathrm{c}}$ & $1.20 \pm 0.99^{\mathrm{c}}$ & $8.44 \pm 1.32^{\mathrm{c}}$ & $16.17 \pm 1.44^{\mathrm{c}}$ & $18.23 \pm 2.21^{\mathrm{c}}$ & $8.88 \pm 1.35^{\mathrm{c}}$ \\
\hline 3 & $1.84 \pm 0.72^{\mathrm{b}}$ & $4.49 \pm 0.89^{\mathrm{b}}$ & $21.61 \pm 1.05^{\mathrm{b}}$ & $38.22 \pm 1.28^{\mathrm{b}}$ & $43.55 \pm 2.74^{\mathrm{b}}$ & $21.94 \pm 1.33^{\mathrm{b}}$ \\
\hline 4 & $2.11 \pm 0.23^{\mathrm{a}}$ & $9.27 \pm 1.08^{\mathrm{a}}$ & $36.69 \pm 2.14^{\mathrm{a}}$ & $53.32 \pm 2.22^{\mathrm{a}}$ & $64.37 \pm 3.56^{\mathrm{a}}$ & $33.15 \pm 1.85^{\mathrm{a}}$ \\
\hline
\end{tabular}

$(\mathrm{n}=1$, Rep. 10, Mean \pm SD)

The first instar tunnelled to a length of $3.2 \pm 0.43 \mathrm{~cm}$ with approximate diameter of $2.4 \pm 0.4 \mathrm{~mm}$ (Table 2).Cross section of the BPW infested plant in the field revealed that the early instar tunnels only the outermost sheath of the pseudostem, and its tunnelling is only in verticaldirection. The first instar lasted for $4.8 \pm 0.79$ days(Table 3 ).
Table 2: Tunnel made by different stages of Odoiporus

\begin{tabular}{|c|c|c|c|c|}
\hline \multicolumn{5}{|c|}{ longicollis } \\
\hline S1 No. & Stage & \multicolumn{2}{|c|}{ Tunnel } & Tunnelling pattern \\
\hline & & Length $(\mathrm{cm})$ & Breadth $(\mathrm{cm})$ & \\
\hline 1 & 1st Instar & $3.20 \pm 0.43$ & $0.80 \pm 0.13$ & Vertical \\
\hline 2 & 2nd Instar & $5.76 \pm 0.34$ & $1.20 \pm 0.04$ & Horizontal \\
\hline 3 & 3rd Instar & $8.86 \pm 1.15$ & $2.43 \pm 0.09$ & Horizontal \\
\hline 4 & 4th Instar & $7.00 \pm 0.74$ & $3.03 \pm 0.14$ & Horizontal \\
\hline 5 & Pre-pupa & $1.06 \pm 0.11$ & $0.45 \pm 0.08$ & Vertical \\
\hline
\end{tabular}

$(\mathrm{n}=20$, Rep. 3 , Mean \pm SD $)$

Table 3: Life cycle of Odoiporus longicollis

\begin{tabular}{|c|c|c|c|c|c|c|c|}
\hline \multicolumn{8}{|c|}{ Life stages (days) } \\
\hline Egg & \multicolumn{9}{|c|}{ Instars } & Pupa & \multicolumn{2}{c|}{ Adult } \\
\hline \multirow{3}{*}{$4.5 \pm 0.71$} & First & Second & Third & Fourth & & Male & Female \\
\cline { 2 - 5 } & $4.8 \pm 0.79$ & $5.2 \pm 0.4$ & $6.4 \pm 0.5$ & $6.9 \pm 0.7$ & $7.2 \pm 0.8$ & $102.7 \pm 17.5$ & $139.1 \pm 12.4$ \\
\hline
\end{tabular}

Volume 5 Issue 6, June 2016 www.ijsr.net 


\section{International Journal of Science and Research (IJSR) \\ ISSN (Online): 2319-7064}

Index Copernicus Value (2013): 6.14 | Impact Factor (2015): 6.391
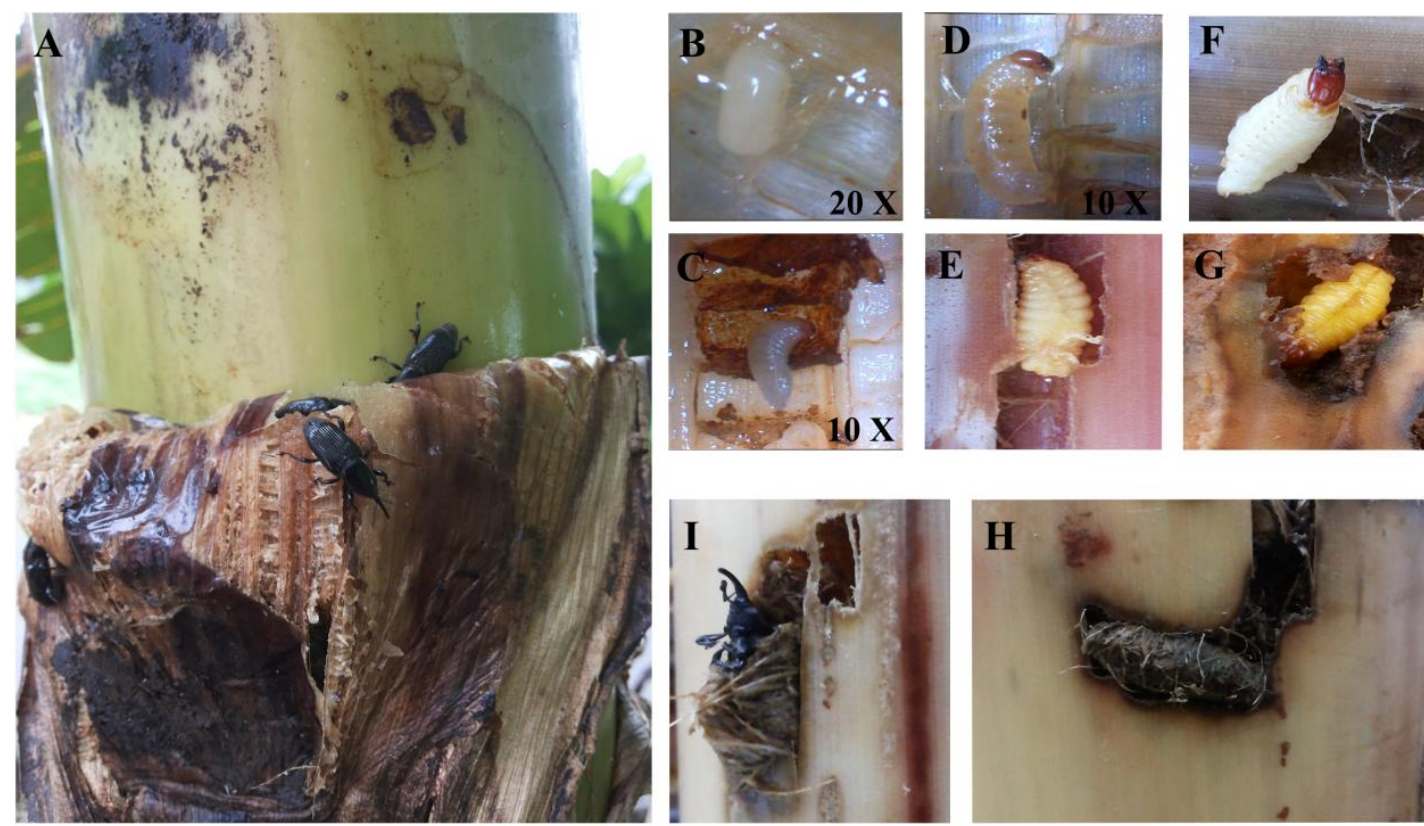

Figure 3: Life cycle of Banana Pseudostem Weevil, O. longicollis.A. Adult weevil on host plant, B. Egg inside the pseudostem sheet, C. First instar larvae, D. Second instar larvae, E. Third instar larvae, F. Fourth instar larvae, G. Pre-Pupae stage, H. Pupa, I. Emergence out from pupation as adult weevil.

The second instar grub had duration of $5.2 \pm 0.42$ days, with a size of $7.12 \pm 0.094 \mathrm{~mm}$ long and $2.93 \pm 0.050 \mathrm{~mm}$ width. Head is reddish brown and it feeds $8.88 \pm 1.35 \mathrm{~g}$ throughout the stage. This instar was usually noticed in the 2 nd and 3 rd outer whorl of the leaf sheaths.

Third instar grub reached to a length of $13.44 \pm 0.152 \mathrm{~mm}$ and width $6.69 \pm 0.073 \mathrm{~mm}$. This instar is leathery, creamy white body and orange red head. Being a voracious feeder, it consumed $21.94 \pm 1.33 \mathrm{~g}$ of pseudostem and tunnelled to an average length of $8.86 \pm 1.15 \mathrm{~cm} /$ day, which is longer $(7.00 \pm 0.74 \mathrm{~cm})$ than the tunnel made by the 4 th instar.In a BPW infested plant, the prominent tunnels seen are made by third instars, which are usually concentrated in the inner sheaths. Third instar lasts for $6.40 \pm 0.52$ days.

Fourth instar grubs (final instar), which measures $17.94 \pm 3.54 \mathrm{~mm}$ length and $8.83 \pm 1.21 \mathrm{~mm}$ width respectively, are thick creamy to yellow in colour and bears tiny cutaneous bristles scattered throughout the body. While feeding the pseudostem, they usually returns back to the outer sheath to undergo pre pupation to pupation, as these sheaths are rich in fibre to make puparium. A window hole is formed onto the pseudostem before its emergence as adult. Fourth instar lasts for $6.90 \pm 0.74$ days, and during this stage it feeds an average of $33.15 \pm 1.85 \mathrm{~g}$ by making a tunnel of $3.03 \pm 0.14 \mathrm{~cm} /$ day. The larvae are confined to first or $2^{\text {nd }}$ outer leaf sheath.

The pre pupal stage is for 2-3 days and it measures $3.2 \pm 0.35 \mathrm{~cm}$ length and $1.37 \pm 0.25 \mathrm{~cm}$ width.It was seen in the $2^{\text {nd }}$ whorl and usually moves downwards. Pupation takes place at the second outer whorl, and its duration is 7.2 \pm 0.79 days. Total life cycle completed in $35.00 \pm 1.83$ days.

Longevity:Adult is tough, shiny black and feed sparsely to a tune of $0.27 \pm 0.02 \mathrm{gm} /$ day. Longevity of BPW is 120.9 days, but in general female lives significantly longer (139.1 \pm 12.41 days) than male $(102.7 \pm 17.47)(\mathrm{P}=0.894)$.
Host preference: In the equal choice test the host preference sequence was Musa AAB Cv. Nendran> Musa AAA Cv. Morris/ Musa ABB Cv. Kappa> Musa AB Cv. Njalipoovan. While Nendran was the most preferred variety, Morris and Kappa were shown as equal preference, and Njalipoovanwas relatively tolerant (Table 4). In the case of Musa AAB Cv. Nendran, $60.32 \pm 2.50 \%$ weevils attracted whereas it was only $2.15 \pm 0.05 \%$ in Musa AB Cv.Njalipoovan.

Table 4: Host variety preference exhibited by adult Odoiporus longicollis

\begin{tabular}{|c|c|c|}
\hline S. No. & Variety of host plant & Preference by BPW (\%) \\
\hline 1 & Musa AB Cv. Njalipoovan & $2.15 \pm 0.05^{\mathrm{c}}$ \\
\hline 2 & Musa AAB Cv. Nendran & $60.32 \pm 2.50^{\mathrm{a}}$ \\
\hline 3 & Musa AAA Cv. Morris & $19.66 \pm 2.15^{\mathrm{b}}$ \\
\hline 4 & Musa ABB Cv. Kappa & $17.87 \pm 2.05^{\mathrm{b}}$ \\
\hline
\end{tabular}

$(\mathrm{n}=5$, Rep. 10, Mean \pm SD)

\section{Discussion}

A comprehensive account on the biology and pest status of the banana pseudostem weevil, $O$. longicollis, was documented by Dutt and Maiti, (1972), subsequently Isahaque (1978) and Shukla and Tripathi (1978), Visalakshiet al.(1989), Padmanabhan and sathiamoorthy (2001), Tiwariet.al. (2006), Thippaiahet al.(2010) and Priyadarshiniet al.(2014), also reported the biology of BPW in general.

Incubation period of egg reported is or on par with the study reports of Justin et al.(2008), Azamet al.(2010), Mohammad et al.(2010) and Tara et al.(2010), nevertheless Dutt and Maiti (1972) had noticed variance in the incubation period according to climate as, 3-5 days in hot and 5-8 days in cold climate of West Bengal, India.The morphometric features of egg observed are exactly on par with the result recorded by Padmanaban and Sathiamoorthy (2001), but Mohammad et al.(2010) reported an increase in its size, $2.21 \pm 0.2 \mathrm{~mm} \mathrm{x}$

\section{Volume 5 Issue 6, June 2016 www.ijsr.net}




\section{International Journal of Science and Research (IJSR) \\ ISSN (Online): 2319-7064 \\ Index Copernicus Value (2013): 6.14 | Impact Factor (2015): 6.391}

$1.12 \mathrm{~mm}$ and the current study report $1.877 \pm 0.062 \mathrm{~mm} \mathrm{x}$ $0.911 \pm 0.010 \mathrm{~mm}$. This negligible variation may be link with the nutritional profiles of the host plant.

According to Justin et.al. 2008, Fecundity of $O$. longicollis is 60-65 egg, which is on par with the current experimental result of 62 eggs. It was also noticed that a $7 \%$ decrease in fecundity was observed when a female is continuously accompanied by a male this was probably due to the courtship interference on egg laying.

Morphometry of egg and larval stages of the current work corroborates with the reports of Justin et.al. (2008), Mohammad et. al (2010), Thippaiahet al.(2011) and Priyadarshiniet al. (2014). Justin et al. (2008) observed variation of body size in accordance with the climatic change. According to Justin et. al (2008) and Priyadershiniet al.(2014) the average ratio of increase in the width for each instar in each climatic season varies and this accounts for Some disputes on the larval length; in the current study it was $17.94 \pm 3.54 \mathrm{~mm} \times 8.83 \pm 1.21 \mathrm{~mm}$ that support the research of Mohammad et al.(2010) and Priyadarshiniet al.(2014).

A detailed account of life cycle of BPW studies has been documented by Isahaque, (1978), Shukla and Tripathi (1978), Visalakshiet al. (1989), Padmanabhan (2001), Tiwariet.al.(2006), Thippaiahet al. (2010) and Priyadarshiniet al., (2014). Life span determined in the current study for the grub from instar 1 to 4 th is in support with the findings of Thippaiahet al., (2011) and Priyadarshiniet al.(2014). The pre-pupal and pupal stages together accounts on an average of 10-11 days, and this finding is in agreement with the observations of Visalakshiet al.(1989) and Priyadarshiniet al.(2014), while Thippaiah et.al. (2011) record it as 17-21 days. Total developmental period of BPW in the current investigation was in agreement with the findings of Visalakshiet al.(1989), Thippaiahet al.(2011) and Priyadarshiniet al.(2014), Pre-oviposition period was 23-28 days and this was in the range previously recorded by Visalakshiet al.(1989), Thippaiahet. al(2011) and Priyadarshiniet. al(2014).

Variation in the longevity of BPW has been reported. Longevity in the current investigation recorded 191 days, and it is closely in agreement with the observation of Ravi and Palaniswami (2002), they report 200 days. However, Pinto (1928) observed it as high as 2 years, but Padmanabhan and Sathiamoorthy (2001), and Thippaiahet. al(2011) reported it was only 44 and 81.0 days, respectively. Priyadarshiniet. al , (2014) studied longevity of both male and female under known temperature and observed, irrespective of sex, the average longevity was 75-80 days.

Host preference of BPW to different varieties of banana was studied by Prasuna (2008),Sahayaraj and Kombiah (2009) and Palanichamyet. al(2011). Prasuna (2008) studied on the flight adaptations of BPW and observed sudden flight response of weevil in search for food after a starving period of $48 \mathrm{~h}$, a similar result was observed in the current study. Females $(65 \%)$ are more attracted to the food source than the males (53.4\%) (Sahayaraj and Kombiah 2009); this was supported by Palanichamyet al.(2011) in their study using microwave oven assisted extract of pseudostem, it was reported that females were more attracted (76.3\%) than males $(23.7 \%)$. Among the different varieties of banana,BPW has preference in feeding, and the most preferred variety was Musa AAB Cv.Nendran followed by Kappaand Morris.Njalipoovan was the least preferred verity(Padmanabanet. al , (2001); Reddy et. al , (2015).Gailceet. al, (2006) in Tamil Nadu Agricultural University (TNAU) also reported that highest incidence of BPW in Nendran variety followed by Poovan, Robusta and Kappa. Non-preferred varieties were documented by Dutt and Maiti (1970) and also opined that physical and chemical characteristics of plant are the factors governing resistance for BPW attack.

\section{Conclusion}

The current study documented the key biological aspects of banana pseudostem weevil and the relevance of preference among various Musa ploids. High fecundity coupled with high viability make the weevil a major pest. The life cycle studies shows BPW lives for almost 5 month and the dominating stage is the adulthood with a negligible preoviposition period and high survival rate. Though the longevity of the insect is a dispute current study typifies the longevity of the weevil in a possible invitro tropical environment. Though host preference studies are abundant the stability of preference varies with time and this study observes Musa AAB Cv. Nendranas the most preferred among other varieties scrutinized.

\section{References}

[1] Anitha Nair. 2004. Clonal susceptibility and age preference of banana pseudostem weevil, Odoiporus longicollis Oliv. Insect Environment, 10 (3): 132-134

[2] AzamMohammad, J S. Tara, ShalooAyri, MohdFeroz and V.V. Ramamurthy. 2010. Bionomics of Odoiporus longicollis Oliver (Coleoptera: Rhynchophoridae) on banana plant (Musa paradisiac). Mun.Ent. Zool. 5 (2): 627-635

[3] David B. Vasantharaj, 2008. Biotechnological approaches in IPM and their impact on environment. Journal of Biopesticides, 1: 01 - 05.

[4] Dutt, N. and B.B. Maiti 1972.Bionomics of the banana pseudostem weevil, Odoiporus longicollis Oliv. (Coleoptera: Curculionidae). Indian journal of entomology. 34: 20-30

[5] Dutt, N. and Maiti, B. B., 1970.Occurrence of three banana pests at Delhi. Indian Journal of Entomology., 14: 60

[6] Gailce Leo Justin C., M. Leelamathi and S.B. Nirmaljohson. 2008. Bionomics and management of the pseudostem weevil Odoiporus longicollis Oliver (Coleoptera: Curculionidae) in banana- a review. Agriculture Review. 29 (3): 185-192

[7] Gailce Leo Justin, C., Rajkumar, D., Nirmalatha, J. D., Prem Joshua, J. and Jayasekhar, M. 2006. Dose optimization of insecticides for the management of the pseudostem weevil Odoiporus longicollis (Coleoptera: Curculionidae) on banana. Agricultural Science Digest, 26: 117-119.

[8] Giblin-Davis, R. M., K. Gerber, and R. Griffith. 1989. Laboratory rearing of Rhynchophoruscruentatus and R.

\section{Volume 5 Issue 6, June 2016 www.ijsr.net}




\section{International Journal of Science and Research (IJSR) \\ ISSN (Online): 2319-7064}

Index Copernicus Value (2013): 6.14 | Impact Factor (2015): 6.391

palmarum (Coleoptera: Curculionidae). Florida Entomol. 72(3): 480-488.

[9] Gold C., Bagamba F., I. W. Ssennyonga, E. Katungi, P. Ragama, A. Katwijukye and W. K. Tushemereirwe. 2001 Current banana production and productivity in Bamunanika sub-country, Central Vganda, Base line study.ICIPE, Nairobi, Kenya.

[10] Gold, C.S. and Messiaen, S. 2000. The banana weevil Cosmopolites sordidus Musa pest fact sheet No 4 INIBAP, Montpellier, France.

[11] Isahaque, N. Md. M. 1978. Note on the incidence of Odoiporous longicollis Oliver on banana in Assam. Pesticides, 12 (6): 22-24

[12] Mohammad Azam, J. S. Tara, ShalooAyri, MohdFeroz and V. V. Ramamurthy, 2010. Bionomics of Odoiporus longicollis Olivier (Coleoptera: Rhynchophoridae) on banana plant (Musa paradisiac)

[13] PadmanabanB., and S. Sathiamoorthy. 2001. The banana stem weevil Odoiporus longicollis, National research centre for banana (NRCB), India. Musa Pest FactCorrespondance.

[14] Padmanaban B., P. Sundararaju and S. Sathiamoorthy. 2001. Incidence of banana pseudostem borer, O. longicollis Oliv. (Coleoptera: Curculionidae) in banana peduncle.Indian J. Entomology 63 (2) 204-205.

[15] Padmanaban B., P. Sundararaju, K. C. Velayudhan and S. Sathiamoorthy. 1999. Evaluation of Musa germplasm against banana weevil borers; INFOMUSA., 10 (1) 2628

[16] Palanichamy S., B. Padmanaban, M. I. Fazal Mohamed and M. M Mustaffa. 2011. A simple and low cost semiochemical based trapping method for the management of banana pseudostem weevil, Odoiporus longicollis Oliver (Coleoptera: Curculionidae), Advances in applied science research, 2 (3): 69-73

[17] Pinto, M. P. D. 1928. The two weevil pests of plantains (Musa sapientum L.): Cosmopolites sordidus Germ. and Odoiporus longicollis Oliver. Tropical Agriculture. 70, 216-224

[18] PrasunaA. L., K. N. Jyothi, A. R. Prasad, J. S. Yadav and B. Padmanaban.2008. Olfactory responses of banana pseudostem weevil, Odoiporus longicollis Oliver (Coleoptera: Curculionidae) to semiochemicals from conspecifics and host plant, Current science, 94 (7): 896-900

[19] PrasunaA. L., K. N. Jyothi, A. R. Prasad, J. S. Yadav and B. Padmanaban.2008. Olfactory responses of banana pseudostem weevil, Odoiporus longicollis Oliver (Coleoptera: Curculionidae) to semiochemicals from conspecifics and host plant, Current science, 94 (7): 896-900

[20] Priyadarshini Indira G., U. Mukherjee and Nagendra Kumar. 2014. Biology and seasonal incidence of pseudostem weevil, Odoiporus longicollis Oliver (Coleoptera: Curculionidae) in banana, Pest Management in horticultural ecosystems, 20 (1): 8-13

[21] Ravi, G. and M. S. Palaniswami, 2002.Evidence for a female-produced sex pheromone in the banana pseudostem weevil, Odoiporus longicollis Olivier. Current Science, 83 (7): 893-898

[22] Reddy Srinivasa D., C. Madhumathi, H.Naveena and L. Rajesh Chowdaryet al., 2015. Field evaluation of Musa germplasm for resistance against banana stem weevil,
Odoiporus longicollis (Oliver) (Curculionidae: Coleoptera) in Kadapa district of Andra Pradesh, 7 (1): 1-4

[23] Reghunath, P., Visalakshi A., Mathew T.B., Mohandas N., Beevi S. N. and Remamoni K.S.1992.Insecticidal management of the pseudostem borer Odoiporus longicollis.Oliv. (Coleoptera: Curculionidae)Entomon, 17 (1-2): 113-115

[24] SahayarajK., and P. Kombiah. 2009. Olfactory response of the banana weevil, Odoiporus longicollis (Olivier) (Coleoptera: Curculionidae) against pseudostem and its crude extract, Journal of Biopesticides, 2 (2): 173-176

[25] Shukla, G. S. and Tripathi, A. K., 1978.Effect of temperature on longevity of Odoipoeus longicollis (Oliv.) (Coleoptera: Curculionidae). Entomological News, 89 (9 \& 10): 249

[26] Tara J. S, Sunil Sharma and RamnikKour. 2010. A record of weevil (Coleoptera: Curculionoidea) diversity from district samba (J\&K), Thebioscan 5 (3): 391-394

[27] ThippaiahM., C. T. Ashok Kumar, C. Shivaraju and A.K. Chakravarthy. 2010. Incidence of banana pseudostem weevil, Odoiporus longicollis (Oliver) in south Karnataka. Pest Management in Horticultural Ecosystems. 16 (1): 50-53

[28] Tiwary, M., et al., 1969. International seminar on integrated pest control, New Delhi, Pp. 60-61

[29] Visalakshi, A. G. Nair, M. Beevi S. N. and Amma, A. M. K., 1989.Occurance of Odoiporus longicollis Olivier (Coleoptera: Curculionidae) as a pest of banana in Kerala. Entomon, 14 (3-4): 367-368. 